\title{
CAMINHOS DO DESENHO NA BAHIA DO SÉCULO XVIII
}

Antônio Wilson Silva de Souza*

RESUMO: O presente texto versa sobre o desenho da Bahia do século XVIII, fazendo um sucinto relato sobre a escolha do tema, a realização da pesquisa, e a abordagem que lhe foi dada. Apresenta uma sucinta análise dos desenhos coletados, destacando as suas características e situando-os dentro do contexto social e religioso da Bahia setecentista.

PALAVRAS-CHAVE: Desenho, Arte, Bahia.

RÉSUMÉ: Ce texte parle du dessin de la Bahia du XVIIIme. siècle, faisant un rapport abrégé du choix de ce thème, de la réalisation de sa recherche, et de son abordage. Il y a encore une caractérisation de ces dessins, en même temps qu' ils sont analysés dans le contexte social et religieux de la Bahia de ce siècle.

MOTS CLÉ: Dessin, Art, Bahia.

*Universidade Estadual de Feira de Santana 
Dentre os diversos modos de expressão humana, encontra-se o desenho, figurando como um dos mais antigos e constantes. $\mathrm{O}$ desenrolar da história de cada sociedade e cultura deixa notar a presença deste modo de expressão. Portanto, tornar-se-ia difícil alcançar uma compreensão do desenvolvimento integral do ser humano sem uma atenção particular ao desenho. Para além de constituir uma dentre as várias formas de expressão, o desenho apresenta-se como poderoso auxiliar de um vasto conjunto de outras expressões e de manifestações artísticas, daí o porquê de Gomes (1996, p. 13) concluir que o desenho "É uma das formas de expressão bumana que melhor permite a representacão das coisas concretas e abstratas que compóem o mundo natural ou artificial em que vivemos". Desde a fase primitiva da sua evolução, o ser humano utiliza-se do desenho como fator colaborativo da sua capacidade de expressão e comunicação. Presente em todas as culturas, o desenho assume conotações variadas, visto que depende do contexto no qual emerge, condicionando-se, inclusive, às aspirações e problemas vigentes na sociedade. Cada cultura cria uma maneira específica de desenhar, assim como possui uma reflexão ${ }^{1}$ própria sobre o desenho. Portanto, o desenho diversifica-se através da pluralidade dos estilos, ora refletindo o andamento do processo histórico, ora preludiando mudanças e, não raro, apresentando-se como elemento indicativo e subsidiário dos estágios de transformação pessoal e coletiva, sempre, porém, subjuntivo das intenções humanas de desenvolvimento pleno. No entanto, ao lado do reconhecimento contemporâneo da importância do desenho, insurge o paradoxo, sobretudo no meio artístico e acadêmico, da constatação de que essa expressão vem sendo muito pouco estudada, por ter sido considerada secundária dentro das artes até muito recentemente. Esse longo preterir do desenho em contraposição à acentuada atribuição de valor à outras expressões artísticas, deu incentivo, há algum tempo, para que se procurasse desenvolver pesquisa sobre a história do desenho. Sob a percepção da lacuna existente em relação à história do desenho no século dezoito e por acolher uma sugestão da professora Maria Helena Occhi Flexor, orientadora 
dessa pesquisa, deu-se início, no limiar do ano 2000, dentro do Mestrado em Artes Visuais do Programa de Pós-graduação da Escola de Belas Artes da UFBA, a pesquisa sobre a temática. Pesquisa que foi concluída satisfatoriamente, e a dissertação, intitulada $O$ desenho na Babia do século XVIII, teve defesa realizada em julho de 2002. Ora a revista A Cor das Letras torna oportuna mais uma transmissão do conhecimento haurido em consequência do estudo sobre a citada temática, corroborando, destarte, para que este texto realize a socialização do saber particularmente almejada e academicamente conveniente.

O estudo sobre a temática do mestrado foi possibilitado em decorrência da inexistência de material bibliográfico a respeito. As obras de historiadores da arte na Bahia, que se dedicaram ao estudo do Barroco, versam sobre as diversas manifestações deste estilo, tais como a arquitetura, a talha, a pintura, a escultura e a ourivesaria, no entanto elas deixam um espaço vazio quanto à manifestação do desenho. Pode-se comprovar tal assertiva, recorrendo-se às obras de renomados autores na história da arte da Bahia, como Marieta Alves, Valentim Calderon, Carlos Ott, o beneditino Dom Clemente Maria Nigra, entre outros, ou mesmo entre os brasilianistas como Germain Bazin, Robert Smith e Roberto Pontual. O locus que não fora reservado ao desenho na reflexão desses autores resultou em um pungente e significativo espaço aberto a uma necessária busca do desenho do século XVIII.

O objetivo principal da pesquisa sobre o tema supra citado foi analisar o desenho da Bahia setecentista, destacando as suas principais características, buscando descrevê-lo, classificá-lo dentro do seu contexto histórico, realizar uma análise iconográfica, além de identificar os materiais de base, de fixação, os instrumentos de execução, seus usos e a formação do profissional durante o período abordado.

Necessário se faz, entretanto, explicar a que concepção de desenho o projeto se ateve, uma vez que essa expressão artística é ampla em suas manifestações. Por exemplo, um projeto arquitetônico, as letras capitais iniciais de textos escritos ou 
impressos, as assinaturas rasas e públicas, o traçado das letras em si, entre outras, são expressões gráficas, mas que de certa maneira têm sido estudadas, mesmo que com enfoques variados, alguns dos quais apenas constituiu objeto de estudo deste projeto. Não se pretendeu também, enfocar o desenho enquanto meio educacional, mas tão somente constatar o ensino do desenho no setecentos na Bahia, medida que serviu para explicar a sua execução e o tipo de artista ou artesão que o executou. $\mathrm{O}$ desenho, alvo principal da pesquisa, foi o desenho enquanto idéia, obra de arte individualizada ou trabalho artístico manifestado como moldura de documentos, como ornamentação de textos, como decoração, aquele desenho, em geral feito à mão, e que, por isso mesmo, evidencia um conhecimento técnico de utilização de materiais, manuseio de instrumentos e muito mais o desenvolvimento de habilidade manual.

O estudo sistemático do desenho da Bahia do século XVIII exigiu pesquisa multidisciplinar e em documentação extremamente variada. Principiou-se, então, a pesquisa por meio da busca de acervo documental pertencente aos arquivos da Bahia. Desta maneira foi feito levantamento de material no Arquivo Público da Bahia, nos arquivos das Instituições religiosas, como da Ordem Terceira do Carmo, Ordem Terceira de São Francisco, Ordem Terceira de São Domingos, da Santa Casa de Misericórdia e do Mosteiro de São Bento, todos sitiados na Cidade de Salvador. Apesar de valiosa a contribuição desses arquivos, a quantidade de material coletado foi insuficiente para que se pudesse documentar, subsidiar e analisar o desenho com bastante profundidade, como se requeria. Portanto, sentiu-se a necessidade de buscar maiores subsídios para o estudo de sua manifestação na Bahia. Assim, levantou-se imperiosa a necessidade de busca, no Arquivo Histórico Ultramarino de Lisboa, onde se pôde coletar maior número de documentação do século XVIII, em que se apresentasse o desenho em quantidade suficiente para fundamentar a pesquisa com sólido embasamento. $\mathrm{O}$ material obtido naquele arquivo foi vasto em relação ao encontrado nos arquivos de Salvador da Bahia, o que 
viabilizou um melhor desenvolvimento da pesquisa em torno do desenho, sobretudo porque toda a documentação pesquisada se referia especificamente à Bahia e, na sua grande maioria, eram manuscritos.

Os desenhos levantados, nos citados arquivos, fazem parte dos seguintes tipos de documentos manuscritos: compromissos de irmandades religiosas, que contêm um material extenso de desenho e pintura, mapas de carga e descarga, importação e exportação de mercadorias, coleções cartográficas, escrituras e processos, que trazem assinaturas rasas e públicas, tratados de arquitetura, manuais de artilharia, figurinos militares, cadernos de desenho da aula militar, etc. Outro material importante que subsidiou o estudo em questão, com numerosos desenhos, foi a Nova Escola para aprender a ler, escrever e contar ${ }^{2}$, da autoria de Manoel de Andrade

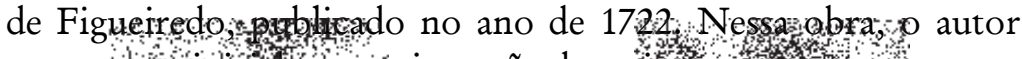
apresenta tanjld

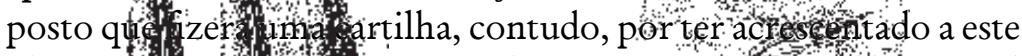

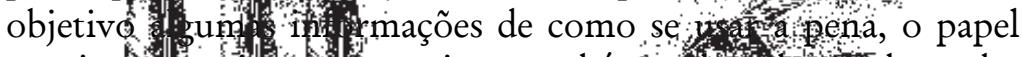
e a tinta, r.m. ornamentar dodument tos, como se pode ver na figurext.
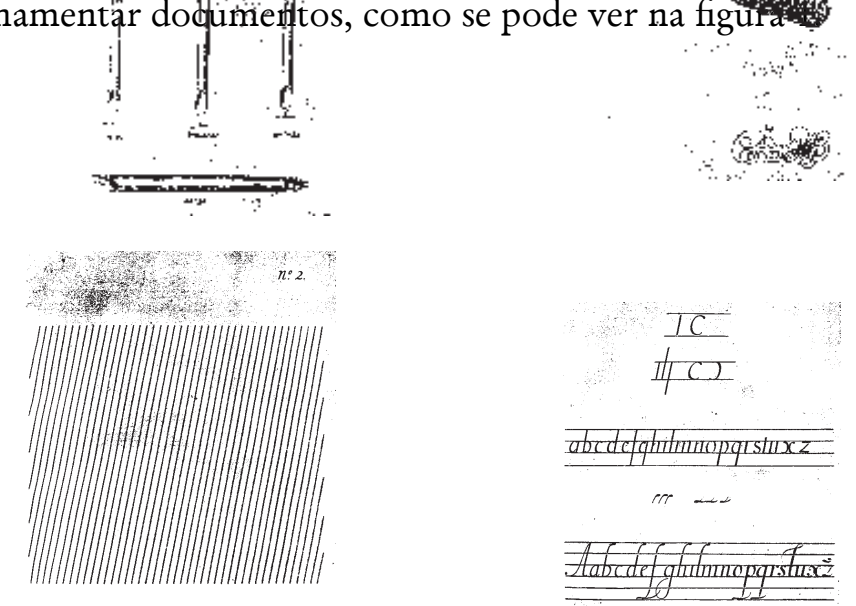

figura 1

Fonte: FIGUEIREDO, Manoel Andrade de. Nova escola para aprender a ler, escrever e contar. Lisboa: Lisboa Occidental, 
Os desenhos encontrados nos documentos citados são, na maioria, de caráter decorativo, mais ornamentais, aparecendo como moldura, sobretudo naqueles dos compromissos de Irmandades. Além de emoldurar os documentos eles aparecem também como elementos ornamentais das capitais iniciais de textos e decoram a folha de papel, na parte inferior, em geral encerrando textos, capítulos. Representam figuras de anjos, querubins, elementos zoo e fitomorfos, coroas, cavaleiros, arabescos simples ou entrelaçados.

A maioria dos desenhos tem um traçado característico feito em curvas entrelaçadas num traço contínuo, sem interrupção para cada elemento realizado. As formas típicas do Barroco sobressaem e se repetem de maneira, às vezes, automática, o que vem evidenciar que os desenhos constituíam uma via de materialização da mentalidade vigente na época.

Há uma padronização que se percebe como uma constante em várias expressões. As assinaturas rasas, por exemplo, apresentam um traçado que se repete em muitas delas. As assinaturas públicas também têm uma forma específica de cruz da qual a haste vertical é bem elevada e em cada extremo da haste horizontal, o nome ou as iniciais do nome do tabelião que a tem como marca pessoal e profissional, registrada em tabelionato para uso nos documentos públicos. No cruzamento das hastes cada tabelião tem um desenho peculiar. Há uma enorme variedade dessas assinaturas, pois cada tabelião deveria criar o desenho que o identificaria profissionalmente. Para os olhos de quem se dedica, hoje, à pesquisa, aquelas assinaturas fazem situar o seu autor dentro de uma determinada época, pois o seu desenho é típico de um período que manifestava um traçado característico da expressão barroca. 
Os desenhos encontrados, nas coleções cartográficas, são também de cunho decorativo e complementar. O enfoque não foi a cartografia em si, mas as legendas. Elas apresentam uma moldura para os dados informativos dos mapas. São desenhos que mostram detalhes de formas que caracterizam esse estilo, como composição de folhas de acanto, e não têm finalidade senão ornamental. Os desenhos das molduras das legendas dessas coleções cartográficas apresentam formas típicas do estilo clássico que fora absorvido e transformado pelo Barroco.

O desenho como idéia aparece na representação de figurinos, desenhos coloridos, realizados para se mostrar como deveria ser a indumentária dos militares, têm uma significação especial, não somente por serem coloridos, mas também por constituírem desenho da figura humana. Esses figurinos manifestam uma visão típica do período barroco, quando o espírito de contradição perpassava a mentalidade e o comportamento do homem daquela época. O semblante dos militares faz alusão a um anjo tipicamente Barroco.

Outros exemplos de desenho como idéia foram levantados ao mesmo tempo em que se buscou exemplares que evidenciassem o desenho como expressão autônoma, o que não foi possível constatar. Outra busca esteve enfocada na relação do desenho, ou risco ${ }^{3}$, com a arquitetura decorativa, pintura, talha, imaginária, trabalhos em couro, os baixo-relevos das lápides tumulares, etc, visto que todas as manifestações artísticas estavam intimamente ligadas pelas formas, pela iconografia e pelo próprio desenho.

Não se deixou, evidentemente, de definir o significado do desenho, ou significados que historicamente ele foi assumindo a partir dos ideogramas, ou representações ideográficas, e como foi influenciado pelas culturas, sobretudo das religiosas, especialmente católicas.

Tendo em mãos este material, foi possível realizar uma análise descritiva e iconográfica que, de muito, contribuiu para o entendimento do desenho e de outras manifestações artísticas da Bahia. Apesar de reconhecer a eficácia do método de Panofsky 
que parte da análise dos símbolos para descortinar e interpretar o conteúdo temático, o significado intrínseco e o conteúdo convencional da obra de arte, deu-se preferência ao método de Ravi Poovaiah ${ }^{4}$, visto que possibilitaria um conhecimento aprofundado e alargado das expressões gráficas, sobretudo porque o referido método se estrutura sobre dois pilares: na natureza sintática do desenho, em termos de elementos, características e princípios visuais, e na dimensão semântica e pragmática do desenho, destacando o conteúdo, o contexto e o código da representação visual. Por essa razão, foi o que melhor se coadunou com o intento de analisar os desenhos do século XVIII.

A análise realizada ofereceu bases para uma reflexão sobre o desenho e, ao mesmo tempo, corroborou para uma melhor compreensão das expressões gráficas da Bahia setecentista. Assim, foi possível destacar com mais nitidez as suas características dos desenhos. Pôde-se, então, constatar que a maioria dos desenhos estudados revelam características do estilo barroco. É forçoso salientar que, na segunda metade da mesma centúria, houve manifestações do estilo rococó, que também se fez evidente nos desenhos ${ }^{5}$. A mentalidade barroca reinante na época orientava de tal forma a maneira de viver das pessoas que as suas expressões, artísticas ou não, revestiam-se de um caráter eminentemente barroco, como provam as assinaturas rasas ${ }^{6}$ do período abordado.

Uma análise sócio-cultural das expressões barrocas na Bahia setecentista mostraria que o barroco foi, mais que um estilo artístico, uma mentalidade filosófica, estética e religiosa da sociedade da época, foi propriamente um estilo de vida, pois pensava-se, vestia-se, falava-se, em realidade, agia-se barrocamente. (SOUZA, 2002, p. 52)

Essa mentalidade, ou melhor, essa maneira de viver caracteristicamente barroca propiciou inúmeras manifestações da arte, como a talha, a pintura, a arquitetura, a música, a escultura, fomentadas pelo espírito religioso, patrocinada pelas Ordens 
Terceiras e, em alguns casos, pelo governo ${ }^{7}$. Contudo não se deixou de dar mostras da expressão eminentemente gráfica, como provam os inúmeros exemplares dos desenhos pesquisados e analisados, na sua grande maioria, como já foi dito, de caráter ornamentativo.

Todo desenho representa em si mesmo uma forma de comunicação, por isso constitui uma linguagem ${ }^{8}$. Dentro desta maneira de entendimento, o desenho pode ser considerado como um caminho através do qual o homem setecentista pôde manifestar a sua visão de mundo. Reflexo de mentalidade e expressão de sentimentos, o desenho utilizou signos específicos do Barroco, ou baseados no vasto mundo de formas próprias desse estilo. Em razão do Barroco ter-se, intrinsecamente, vinculado ao espírito religioso da sociedade da Bahia do século em questão, o repertório de signos pelo desenho apresentado constitui uma vasta quantidade de elementos típicos da manifestação da fé cristã. E, sendo a mentalidade do século dezoito, eminentemente, barroca, as ornamentações dos documentos, mesmo civis, eram um esboço do carácter religioso constituinte da vivência do homem da época.

$\mathrm{O}$ Barroco não renegou as formas clássicas, mas as transformou de modo fantasista e subjetivo. Por esta razão, se pôde reconhecer, nos desenhos analisados, traços da arte clássica acrescidos de características formais propriamente barrocas, como por exemplo, a intensa movimentação, obtida pelo predomínio de linhas diagonais, os fortes contrastes como, por exemplo, o claro e o escuro, as curvas, a sinuosidade, as ondulações, os entrelaçados e o excesso de ornamentação. A decoração da capa de um compromisso de Irmandade da Bahia do século XVIII, figura 2, serve como ilustração comprovativa do que se acabou de afirmar. 


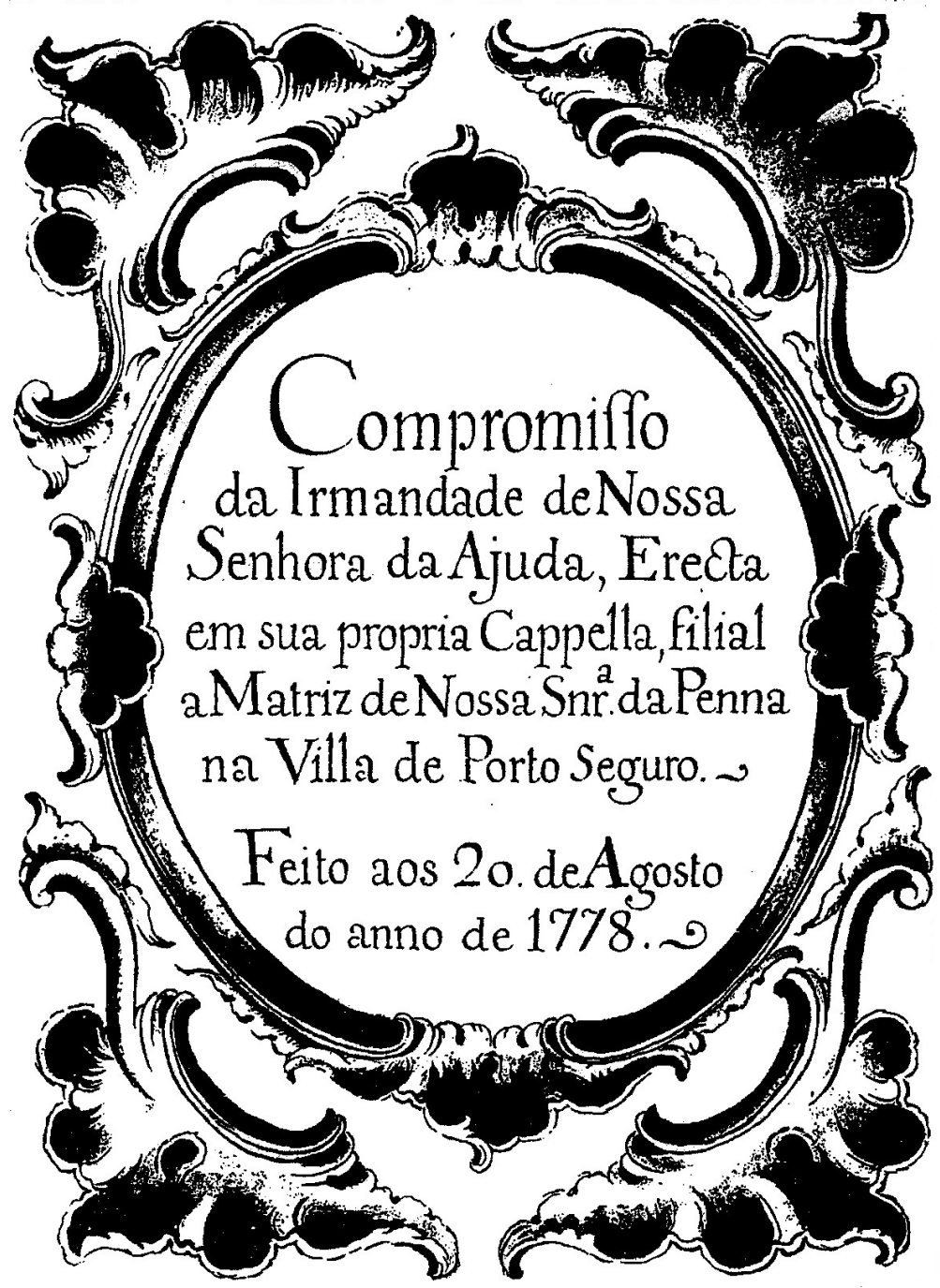




\section{figura 2}

Capa do Compromisso da irmandade de Nossa senhora da Ajuda da Vila de Porto Seguro, Bahia, 1778. Fonte: Códice 1668 do Arquivo Histórico Ultramarino de Lisboa.

No Brasil, notadamente na Bahia, a arte barroca se tornou um instrumento de manifestação do sentimento religioso, de maneira que resulta quase que impossível dissociá-la do contexto da fé cristã. Todavia, apesar da preponderância da fé, uma das tônicas do Barroco é o espírito de contradição que se exprimiu inúmeras vezes na dicotomia entre o profano e o sagrado. Assim, os desenhos evidenciaram também essa característica do citado estilo, quando muitos dentre eles representam em sua ornamentação uma coroa real, símbolo do poder terreno, ao lado de anjos, símbolos da dimensão ultraterrena, ou espiritual.

O Barroco, portanto, foi um seguro caminho que a Bahia setecentista escolheu para manifestar de forma plurissignificativa a linguagem do desenho, embora esta linguagem tenha permanecido secundária em relação às outras expressões artísticas.

Sem pleitear dimensionar vantagens entre as manifestações artísticas, o Barroco não poderia estar melhor representado do que pelo desenho que, com mais clareza que outras expressões da arte, materializou a mentalidade do homem setecentista. A análise dos desenhos fez compreender que as formas e símbolos, por eles representados, integram uma concepção de mundo especialmente religiosa, transmitida por uma linguagem cujo código identifica o estilo barroco e revela influência da cultura portuguesa.

Pelo exposto, uma constatação insurge para reafirmar e reforçar, ainda mais, a concepção que se apresentou no desenrolar deste texto: o desenho é um componente basilar do universo de expressões do homem da Bahia setecentista, e por essa razão, fez-se 
presente como uma manifestação dentre as outras manifestações da arte da época. Essa constatação, porém, não impediu de reconhecer que o desenho setecentista não possuía carácter autônomo.

pôde-se concluir que o desenho foi uma manifestação constante e largamente utilizada em todo o século XVIII, reverberou a mentalidade e a visão de mundo características da época, integrou o universo de manifestações peculiares da arte daquela centúria e constituiu um caminho de expressão barroca do pensamento e da cultura material da sociedade setecentista da Bahia.

\section{NOTAS}

${ }^{1}$ Usa-se aqui a expressão "reflexão" para designar não o discurso intelectivo sobre o desenho, pois este é relativamente muito recente, mas para referir-se a toda intenção que conduz as diversas sociedades e culturas a desenhar.

${ }^{2}$ Essa obra impressa, que contém desenhos feitos à mão pelo próprio autor, passou pela aprovação de todas as instâncias necessárias, em Portugal, inclusive pelo crivo da Mesa de Consciência e Ordens e só assim foi publicada. Urge ressaltar que o autor nasceu no Brasil, filho do Governador e Capitão General do Espírito Santo. Esse material foi fornecido por Maria Helena Occhi Flexor, que obteve cópia microfilmada no Instituto de Estudos Brasileiros da USP.

${ }^{3}$ Termo comumente utilizado em Portugal e no Brasil, durante o século XVIII, para designar os desenhos. Era um sinônimo da palavra "desenho".

${ }^{4}$ Ravi Poovaiah nasceu na Índia, em 1954 e formou-se em engenharia mecânica pelo Instituto Indiano de Madras, em 1975. Em 1977, pós-graduou-se na área de projeto de produto no Instituto de Tecnologia de Bombai, Índia. De 1982 à 86, foi professor do 
curso de Desenho industrial de Bombai. Fez o mestrado na área de Comunicação Visual pela Escola de Desenho da Ilha do Rhode, em Providence, EUA. Tornou-se Professor Adjunto no Instituto de Desenho Industrial de Bombai. Suas linhas de pesquisa, desde 1986, são: estudo dos princípios da representação gráfica bidimensional, estudo da linguagem visual, desenvolvimento de padrões para sinalização urbana, desenvolvimento de sinalização de hospitais e desenvolvimento de fontes tipográficas para computador. Hoje ele é Phd.

${ }^{5}$ Deu-se preferência, neste artigo, ao estudo do desenho barroco, reservando para um próximo texto uma mais aprofundada e detalhada explanação sobre o desenho rococó, merecedor por seu turno, de estudo sistemático, posto que também integra o arsenal de manifestações artísticas da Bahia do século XVIII.

${ }^{6}$ Chama-se de assinatura rasa a assinatura pessoal de um indivíduo.

${ }^{7}$ No século XVIII as Ordens Terceiras (de leigos) eram mais fortes que as Primeiras (de sacerdotes), visto que àquelas se agremiavam, em geral, pessoas abastadas da sociedade da época. Com a contribuição financeira dos Irmãos Terceiros e também com a verba do governo para a construção do altar-mor das igrejas, foi desenvolvida a maioria das obras da arte religiosa da Bahia setecentista.

${ }^{8}$ Por linguagem, neste texto, deve-se ser entendido todo e qualquer sistema de signos que serve de meio de comunicação individual, e entre indivíduos, e que pode ser percebido pelos órgãos dos sentidos. Não se pretendeu, ao longo presente artigo, enfocar questões mais profundas relativas à concepção do desenho enquanto linguagem. Já há autores de renome que se debruçaram e vêm se debruçando sobre esta temática assaz relevante para o desenvolvimento da reflexão sobre a história do desenho. 


\section{REFERÊNCIAS}

\section{Manuscritos}

Compromisso da Irmandade do Senhor Bom Jesus dos Aflitos e Boa Sentença, Bahia, 1778. p. 5. Fonte: Códice 1671 do Arquivo Histórico Ultramarino de Lisboa.

Compromisso da Irmandade de Nossa Senhora da Ajuda da Vila de PortoSeguro, Bahia, 1778. Fonte: Códice 1668 do Arquivo Histórico Ultramarino de Lisboa

Figurinos Militares da Bahia. Arquivo Histórico Ultramarino,1771, Cod. 1510, s.n.p.

\section{Impressos}

FIGUEIREDO, Manoel de Andrade. Nova escola para aprender a ler, escrever e contar. Lisboa: Lisboa Occidental, 1722. p. 155.

FLEXOR, Maria Helena Ochi. Pesquisa e metodologia em arte. Salvador, 1999. (Digitado).

GOMES, Luiz Vidal Negreiros. Desenhando: uma panorama dos sistemas gráficos Santa Maria: UFSM, 1998. p. 172.

. Desenhismo. Santa Maria:UFSM, 1996. p. 119.

MUSEU DE ARTE MODERNA DO RIO DE JANEIRO. Coleção Gilberto Chateaubriand: o desenho moderno no Brasil. Rio de Janeiro: MAM, 1995. 